\title{
The Framework for Building Smart Cities Application using IoT and Cloud Based Architecture
}

\author{
Prof. Sunil Kumar Yadav ${ }^{1}$, Miss. Ashwini T. Pawar ${ }^{2}$, Miss. Monika A. Shelar ${ }^{3}$, Miss. Manali A. Pachpande ${ }^{4}$, \\ Mr. Mayur Barhate ${ }^{5}$ \\ Assistant Prof. ME Comp, Siddhant College of Engineering ${ }^{1}$ \\ BE Comp. Siddhant College of Engineering ${ }^{2,3,4,5}$
}

\begin{abstract}
Prime Minister Narendra Modi came up with new ideas of Smart City and took initiative in it. This project presents some new points which will be used in Smart city. Smart City technologies uses cloud-based and Internet of Things (IoT) based services in which real-world user interfaces use smart phones, sensors and bluetooth. In Smart city all devices are connected with each other through Internet and Wifi. This paper addresses the convergent domain of cloud computing and IoT for any smart city application deployment. A large number of people moving towards urban cities. This situation has created an urgency for finding smarter ways to manage the challenges and to win over it. These all things will lead to Smart city.
\end{abstract}

Keywords: Internet and Wifi, Smart city, IoT, smart phones, sensors and bluetooth.

\section{INTRODUCTION}

Many times the garbage bins placed in city gets overflow due to increase in the waste everyday and which creates unhygienic condition for the people and even city looks bad and even there is bad smell in the surrounding so to tackle these problems IR sensors are used. Now a days the traffic problem has became a major problem everywhere as it even leads to pollution in that particular area so Traffic density is reduced by giving the proper alert to divert the way which will reduce the traffic problem. Security of people is also important in day today life as many unwanted things are occurring in cities like kidnapping, robbery or any kind of harassment etc to tackle this problem security app is used using gesture pattern. Security is also required outside the banks, ATM, jewellary shops and many other places were the people at this place is not allowed as robbery and so on can takes place so to take care of all these things Motion detection is done to keep that place more secured from unwanted things.

\section{MOTIVATION}

As mentioned, a smart city utilizes ICTs in a way that addresses quality of life by tackling urban living challenges encompassed by more efficient utilization of limited resources (space, mobility, energy, etc.). World leading municipalities, in terms of services and quality of life, have provided efficient services to their citizens by the forward thinking and use of technology in monitoring various environmental parameters. Most of these systems consist of sensor, data storage device, and computer at a base station where experts analyze the data. Since the days, cities have been the engines of economic growth. The development was not always "smart", sacrificing health conditions, for instance, for greater productivity. Now with greater use of technology, a number of cities are accumulating data, delivering innovation, and enhancing lives of citizens. It tackles the urban living challenges by more efficient utilization of limited resources ie space, energy etc. According to safety point of view some actions must be taken in order to save the life of people as many of them lost their life due to Diseases, Accidents etc.

\section{SYSTEM ARCHITECTURE}

Cities with heavy populations require lot of energy, water, buildings, public places, transportation and many other things. Therefore, need to find out solutions that are smart which means they are efficient and feasible for economic growth of the city and society as well. These are the 4 Modules which will be used in smart city like

A. Intelligent Bin

B. Intelligent Traffic Density Monitoring

C. Intelligent Security

D. Video Surveillance (Motion Detection) 
These modules describes as follows:

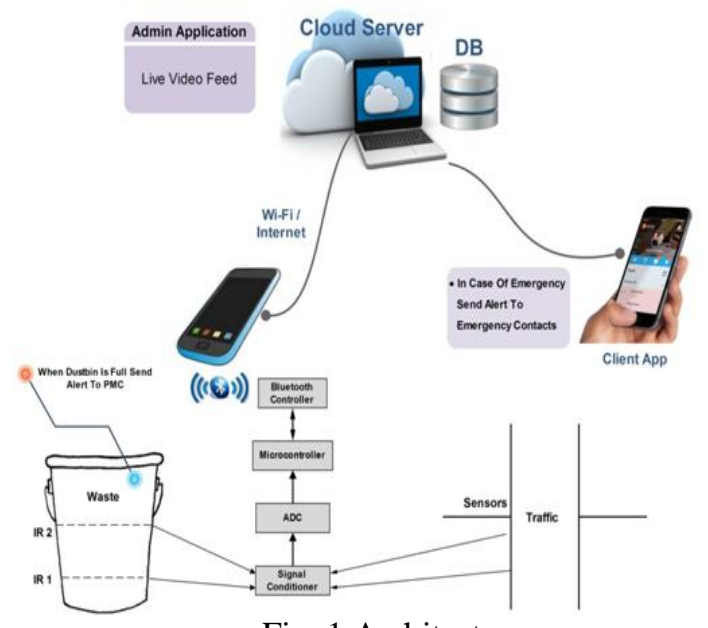

Fig. 1.Architecture

A. Intelligent Bin

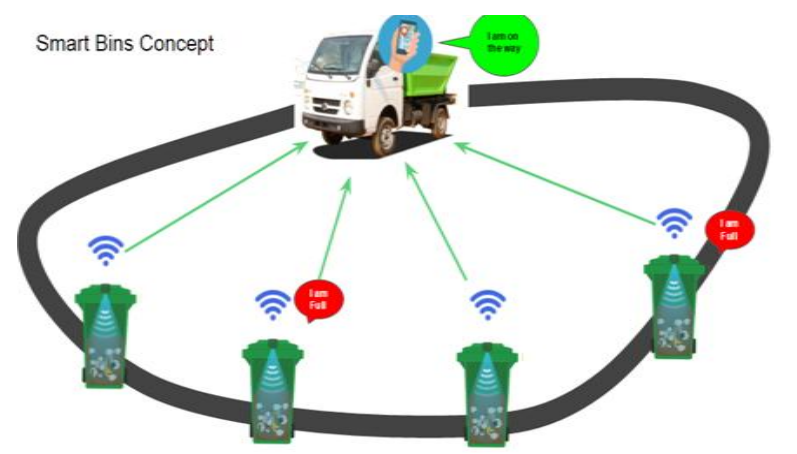

Fig. 2.Smart Bin

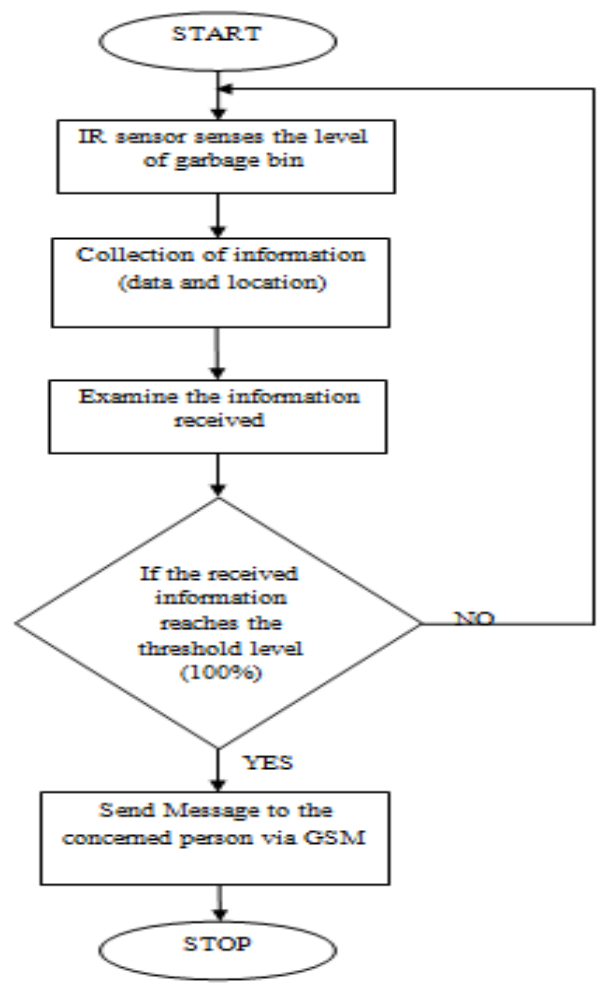

Fig. 3.Flowchart of Bin 
For detecting the garbage, many sensors like weight sensors, IR sensors, etc can be used. Weight sensor is the one which gives the information about the weight of garbage. But using this is not efficient because it doesn't identify the level of waste in the bin. Hence Infrared sensor (IR sensor) is used which is a multipurpose sensor, which can detect the level of garbage.

If the bin is full upto $100 \%$ then send message to the concerned person with proper location.IR sensor is used which senses the garbage level when it reaches the threshold. When the threshold level is reached the information of how much level the bin is filled, location of the bin, date and the current time when the dustbin get filled are all obtained.

B. Intelligent Traffic Density Monitoring

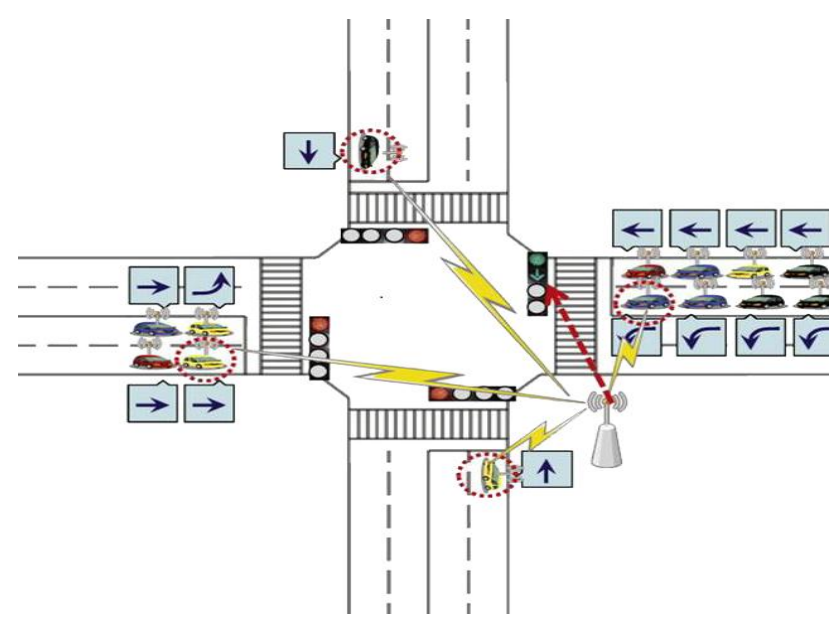

Fig.4.TraffficMonitoring

The traffic problem has became a major problem everywhere as it even leads to pollution in that particular area. In this system for detecting the traffic IR sensors are used. The threshold value is set for all sensors. As per the sensors senses the vehicle at a particular level and then gets the actual idea of traffic to the user. Traffic density is reduced by giving the proper alert to the user so that he/she will divert the way which will reduce the traffic problem.

\section{Intelligent Security}

Security of people is also important in day today life as many unwanted things are occurring in cities like kidnapping, robbery or any kind of harassment etc to tackle this problem security app is used with proper functioning. When the user is in physical violence (robbery, sexual assault etc.).

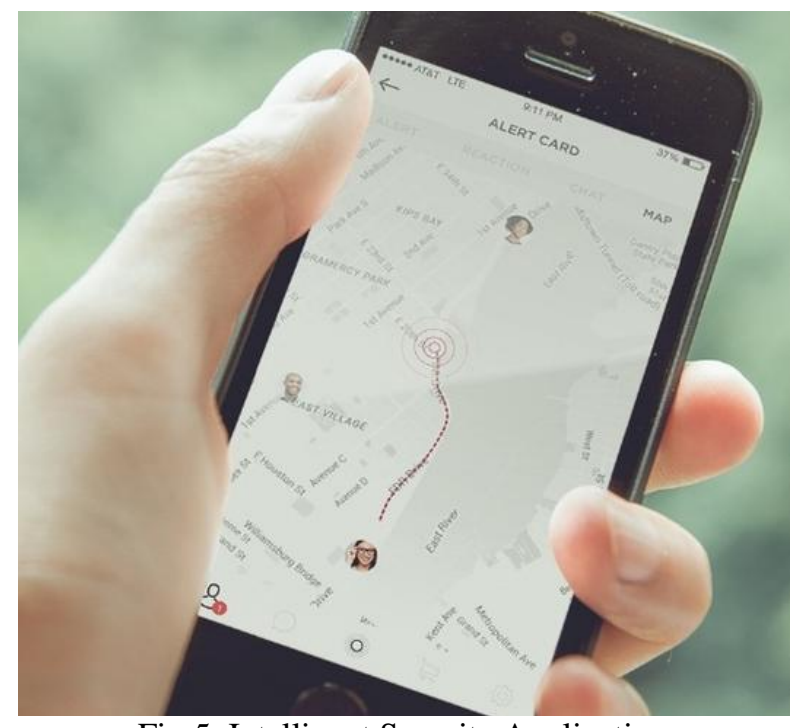

Fig,5. Intelligent Security Application

$\mathrm{He} / \mathrm{she}$ uses that emergency app by reporting the situation where it is raised by clicking on contact number. This emergency message will be send to that contact no with latitude and longitude so that a person who got this emergency 
message will know about that location.This message will be sent to that contact number as " PLZ HELP...PLZ HELP I AM IN DANGER...”..

D. Video Surveillance (Motion Detection):

There are many cameras which are used for detection and it works like dumb because these cameras only store the data but doesn't alert the main authority about the suspicious act. There are two modules under this video surveillance:

1)Live video feed: Instead of using CCTV we make use of android camera for live storage because as compare to CCTV the cost of android camera is lower

2)Motion Detection: The motion detection efficiently detects the intruder and tracks its motion.

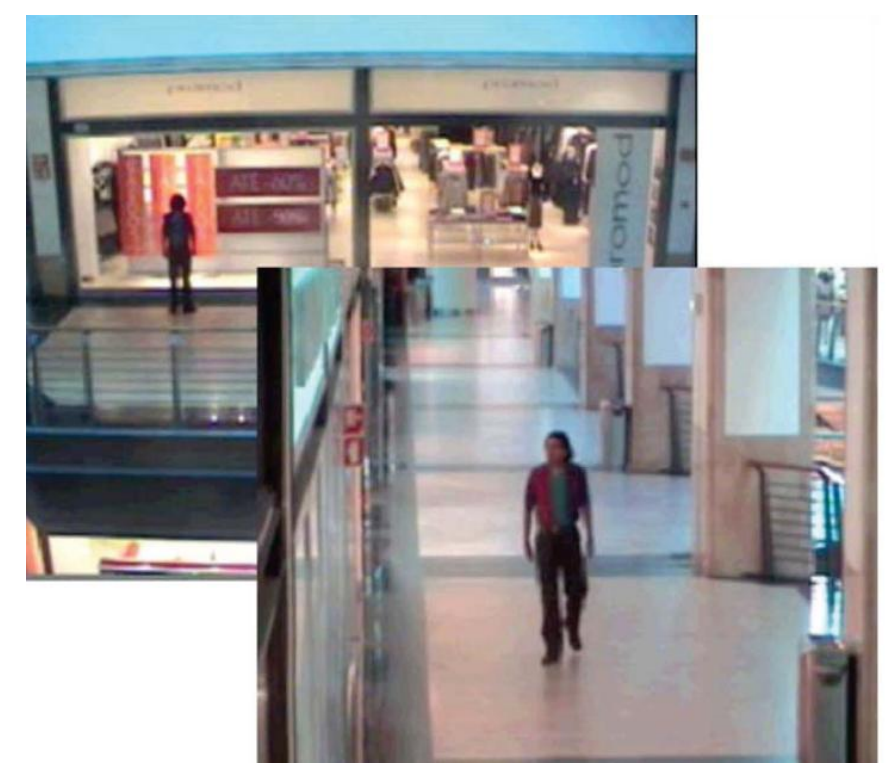

Fig.6. Video Surveillance

Security is also required outside the banks ,ATM ,Jewellary shops and many other places were the people are not allowed as robbery and so on can takes place so to take care of all these things Motion detection is done to keep that place more secured from unwanted things.

\section{RESULTS}

Followings are the results of the system which we are generated.

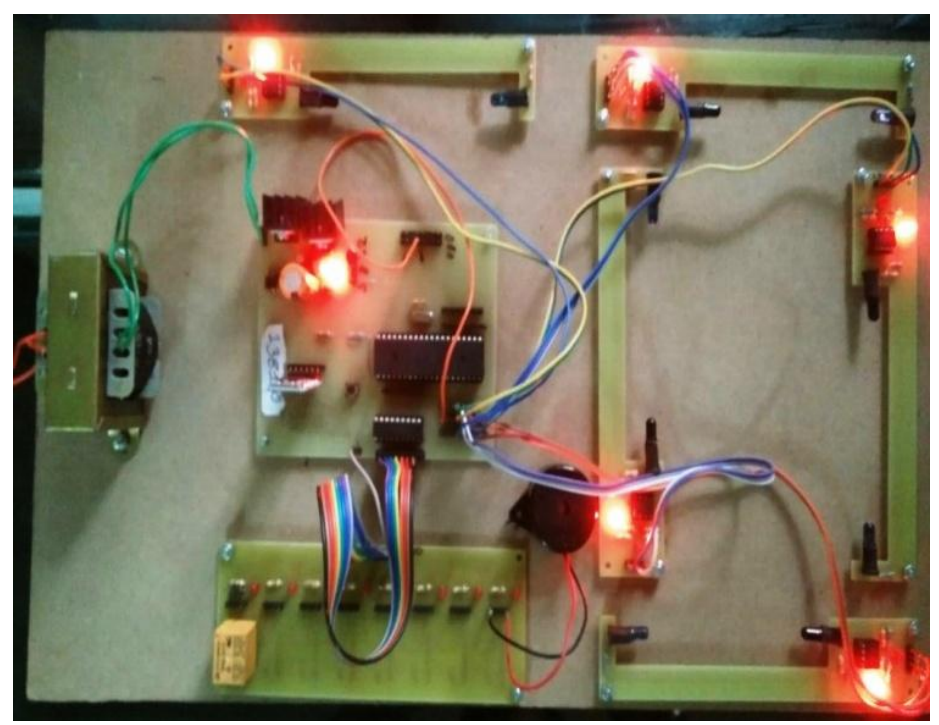

Fig.7.Main Kit of System 
Fig.7 shows Main kit of the system. It shows all functionality of the system. In this diagram we are using IR Sensors, Microcontroller, Transformer, LEDs, Resistors, Buzzer etc. The Kit performs the proper functionality and gives the proper output.

\section{A. Login for the Admin}

Admin use the Username and Password for getting login in the system.

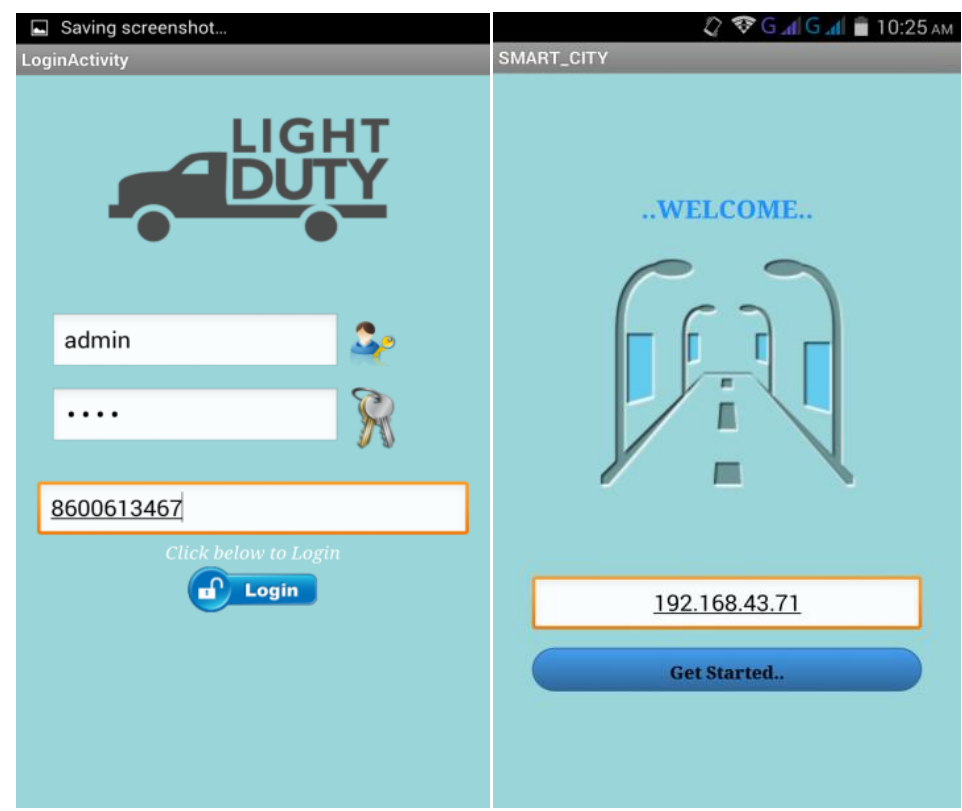

Fig. 8.Admin Login

The above Screenshots i.e. fig. 8 shows the Login activity of the admin.

B.Result of the Intelligent bin

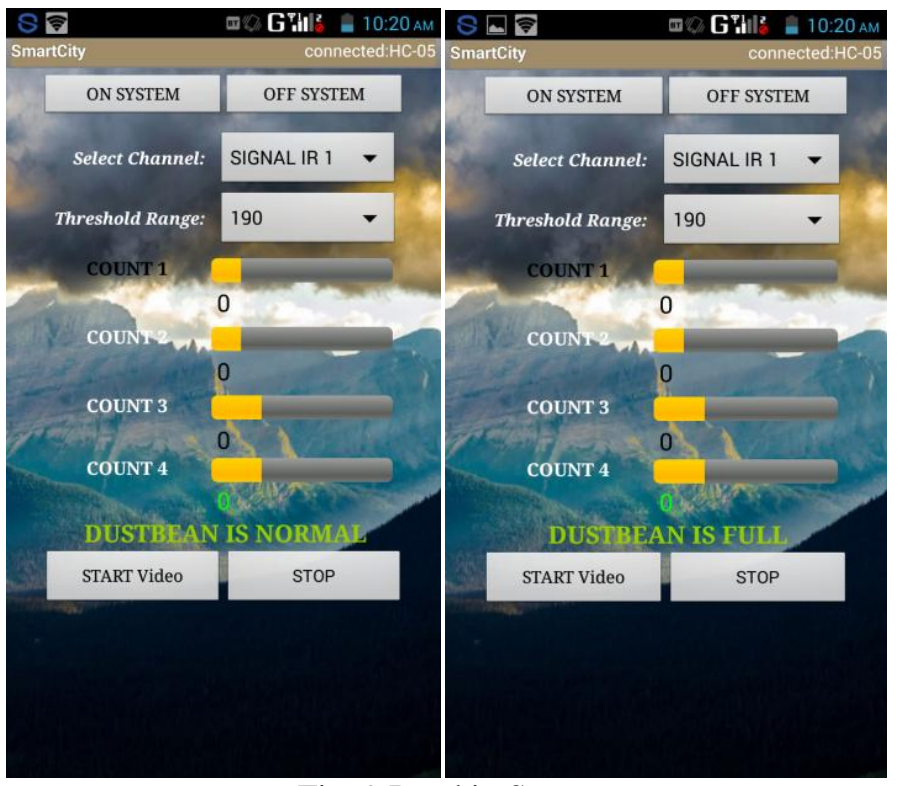

Fig. 9.Dustbin Status

The above screenshots i.e. fig, 9 shows the status of the dustbin. If dustbin gets full in any particular area then the status of the dustbin will automatically show in admin side and also it will send the message to the garbage collector with location. Then garbage collector will collect that all garbage so that the smart city will become a clean city as well. 

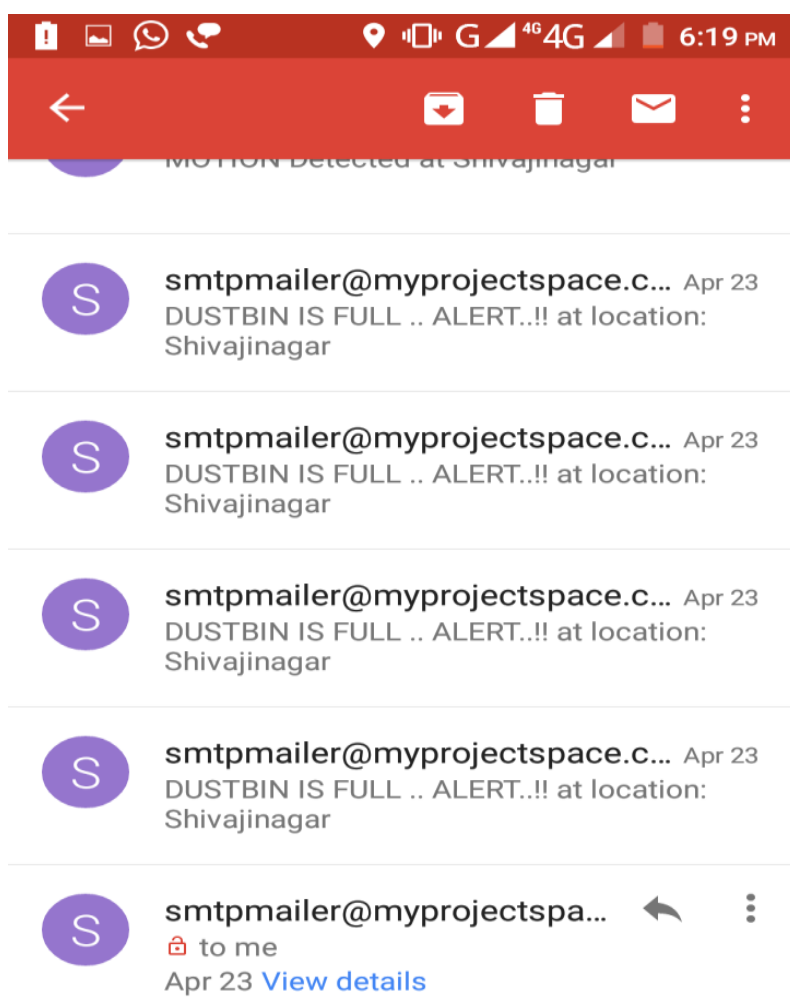

Fig. 10.Mail From Server

C. Result of the Intelligent Traffic

The below Screenshots i.e. fig. 10 shows the traffic density of the roads. How many vehicles passed on a particular road then the system counts the density of the vehicles and send the status to the admin and user also. After that if somewhere any signal occur on road then the user app automatically shows the status of that road with location to the user. So that user can change its path.

Fig. 10 indicate that traffic density of road 2 and road 3.

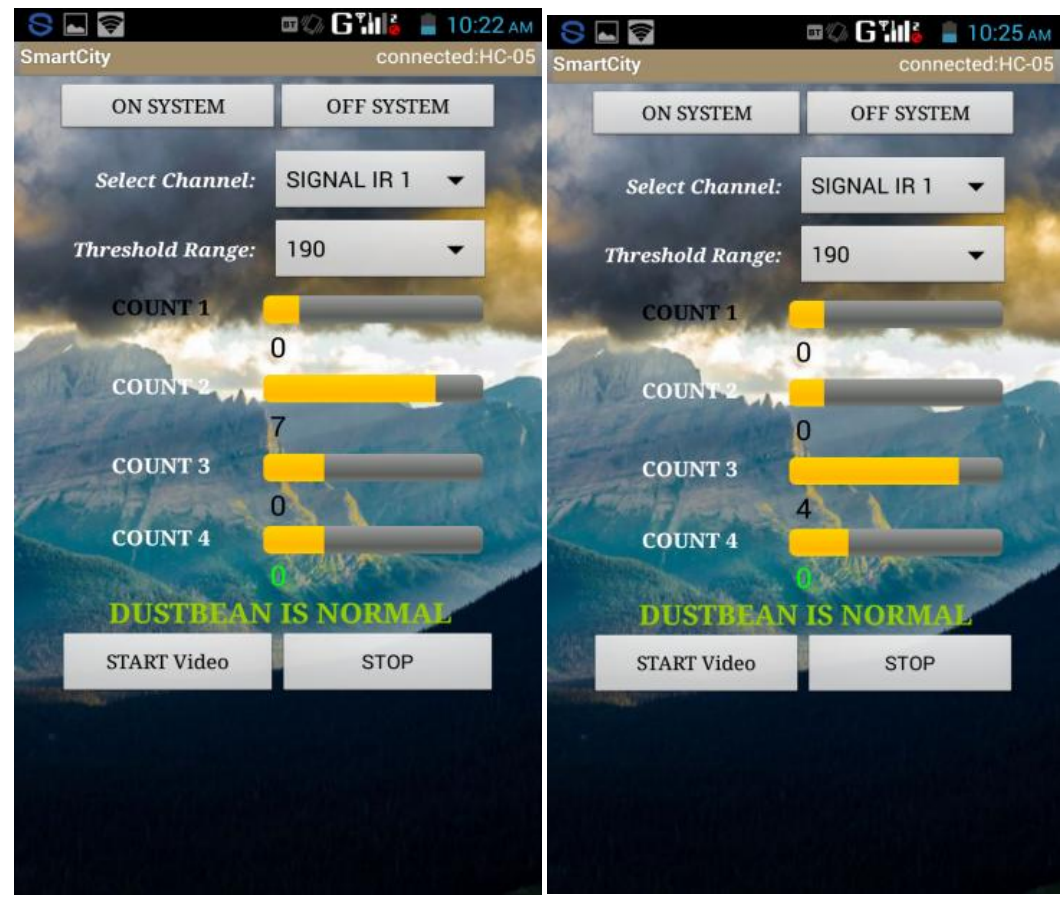

Fig. 11.Traffic density of Road $2 \& 3$ 
D. Result of video surveillance(Motion Detection)

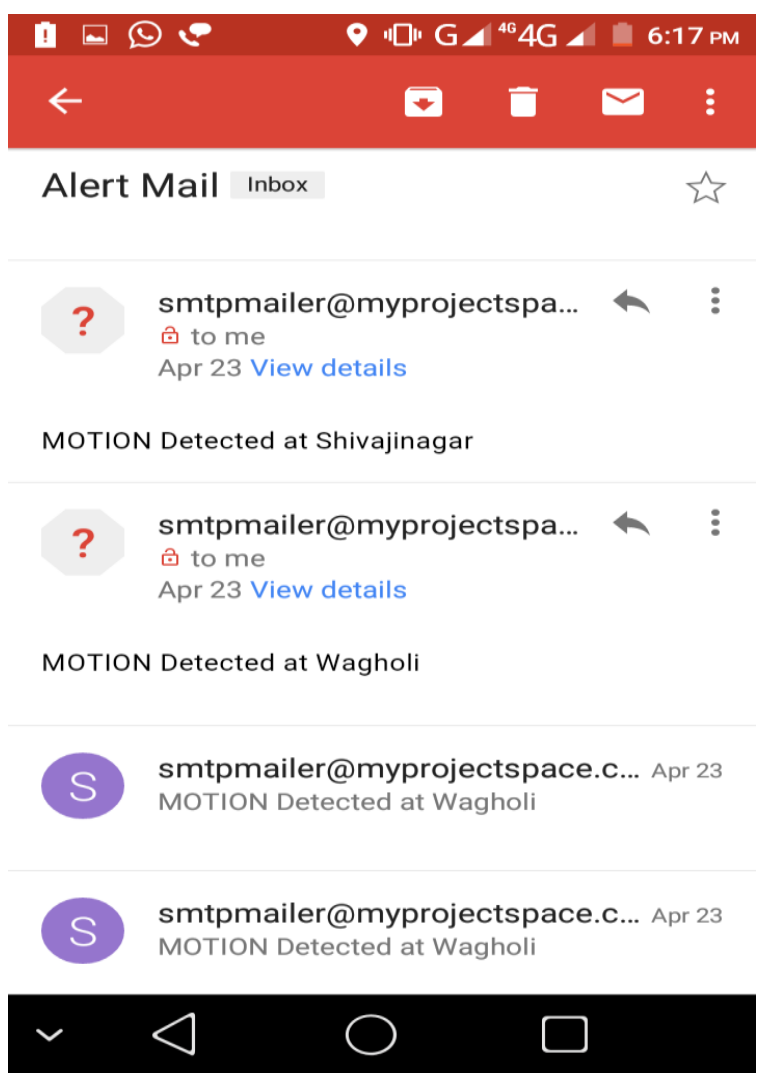

Fig. 12.Mail of Motion Detection

\section{APPLICATION}

There are many Smart City applications in cloud environment.

Telecom - Telecom connectivity lies at the core and forms the backbone of a smart city. In 2014, Du, a leading UAEtelecom provider, announced that as a part of Dubai's smart city initiatives, it would create 5000 hotspots to offer free wi-fi at 100 locations in Dubai and Abu Dhabi. Etisalat and Huawei recently signed an MoU which willdeepen the

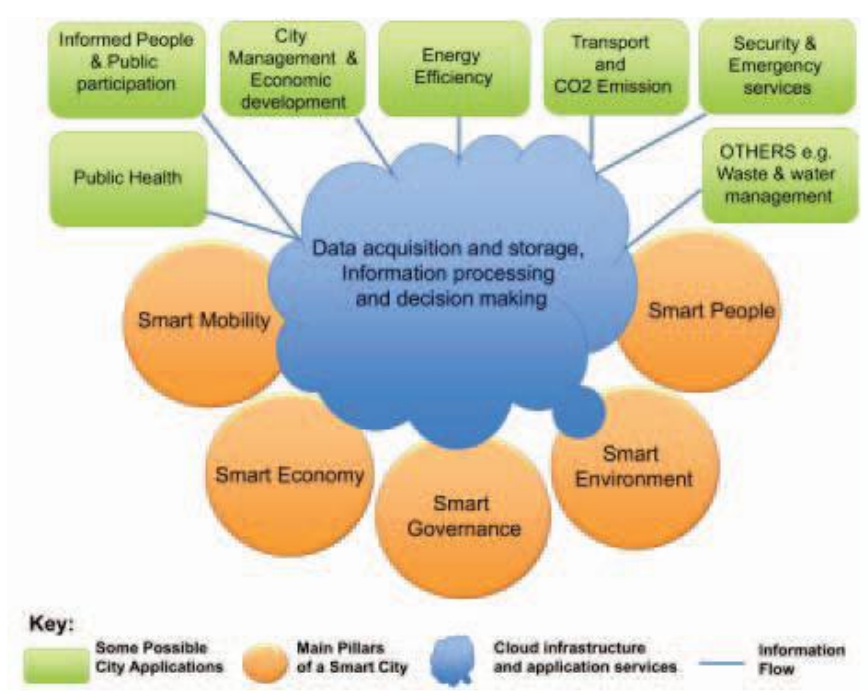

Fig. 13.Smart city application

Android Application is made for all users in Smart City. This android app is used as Monitoring app which will be useful for city members. Through this app all members will get information and safety about:- 
1.) Traffic density on particular road in smart city will be known to all by using this monitoring app.

2.) In this app even dust bin status will be displayed according to particular area so that the area will be always remain clean.

3.) When their is any Emergency this app will be helpful for all members to save them self from any problems and they will be secured.

\section{CONCLUSION}

With rapid development in the emerging IoT technology, we give, in this system, a comprehensive blueprint of developing as mart city using IoT, which is actually motivated and strongly demanded from city councils as they seek to ensure the provision of essential services and quality of life for city inhabitants. In this system, the garbage managing system and the facility of collecting the garbage presently doesn't fit to the current requirement. Hence better facility of collecting garbage and transportation should be provided. Since, this system provides the information when the bin gets completely filled with garbage, it reduces the number of times the arrival of vehicle which collects the garbage. The smart traffic management system using IR which will eliminate the drawback of the existing system such as high implementation cost. The security app provides the better security as compare to other applications which is very needful in current situation. The motion detection is also takes place with the help of this system.

\section{ACKNOWLEDGMENTS}

We take this good opportunity to specially thanks our project guide PROF. SUNIL KUMAR YADAV works under the department of Computer Engineering, Siddhant college of engineering, sudumbare for his valuable guidance, suggestion and encouragement in the completion of this project.

Our special thanks to prime minister Narendra Modi Sir who took initiative to launch the "Smart City Project" in 2016 and even Modi sir invited new ideas for the "Mission Swacch Bharat".

The "Smart City Project" and "Mission Swacch Bharat" dream of our PM encouraged us to work on this type of project and to find various solutions over it so that each city will become smart city and also clean city.

\section{REFERENCES}

[1] J. Gubbi, R. Buyya, S. Marusic, and M. Palaniswami, Internet of Things(IoT):A vision, architectural elements, and future directions, Future Gener. Comput Syst., vol. 29, pp. 16451660, 2013.

[2] R. V. Kulkarni, A. Forster, and G. K. Venayagamoorthy, Computational intelligence in wireless sensor networks: A survey, IEEE Commun.Surveys Tutorials, vol. 13, no. 1, pp. 6896, Feb. 2011.

[3] M. Conti, S. Chong, S. Fdida, W. Jia, H. Karl, Y.-D. Lin et al., Research challenges towards the Future Internet, Comput. Commun., vol. 34, no. 18,pp. 21152134 , Dec. 2011.

[4] J. Gubbi, S. Marusic, Y. W. Law, A. S. Rao, and M. Palaniswami, A pilot study of urban noise monitoring architecture using wireless sensor networks, in Proc. Int. Conf. Advances Comput. Commun. Informat. (ICACCI), Bangkok, Thailand, Sep. 2013.

[5] M. Palaniswami, S. Marusic, J. Gubbi, and Y. W. Law, Noise mapping: Designing an urban information architecture to record and map noise pollution, Univ. Melbourne, Melbourne, Australia, Tech. Rep., May 2011.

[6] A. Gluhak, S. Krco, M. Nati, D. Pfisterer, N. Mitton, and T. Razafindralambo, A survey on facilities for experimental Internet of Things research, IEEE Commun. Mag., vol. 49, no. 11, pp. 5867, Nov. 2011

[7] An Intelligent Security System for Violence against Women in Public Places,"Remy George, AnjalyCherian.V, Annet Antony, HarshaSebestian, Mishal Antony, Rosemary Babu. T ",International Journal of Engineering and Advanced Technology (IJEAT)ISSN: 2249 8958, Volume-3, Issue-4, April 2014

[8] SMART GIRLS SECURITY SYSTEM,"Prof. Basavaraj Chougula1, Archana Naik2, Monika Monu3, Priya Patil4 and Priyanka", Das5International Journal of Application or Innovation in Engineering \& Management (IJAIEM) Volume 3, Issue 4, April 2014 ISSN 2319 4847

[9] MAGESH KUMAR.S and RAJ KUMAR.M, "IPROB - EMERGENCY APPLICATION FOR WOMEN", Department of Computer science Sree Krishna College of Engineering Unai village Vellore (TN) India, ISSN 2250-3153 International Journal of Scientific and Research Publications, online at the link www.ijsrp.org , Volume 4, Issue 3, March 2014

[10] Dongare Uma, Vyavahare Vishakha and Raut Ravina, “An Android Application for Women Safety Based on Voice Recognition”, Department of Computer Sciences BSIOTR wagholi, Savitribai Phule Pune University India, ISSN 2320-088X International Journal of Computer Science and Mobile Computing (IJCSMC) online at www.ijcsmc.com,Vol.4 Issue.3, pg. 216-220, March- 2015

[11] Samy Sadek, Ayoub Al-Hamadi, Bernd Michaelis, Usama Sayed A Statistical Framework for Real-Time Traffic Accident Recognition, Issue: 2010.

[12] Singh, A.P*. Agarwal P.K**., Sharma A.** ROAD SAFETY IMPROVEMENT: A CHALLENGING ISSUE ON INDIAN ROADS , International Journal of Advanced Engineering Technology April-June, 2011

[13] Zembedded, GSM modem interfacing with 8051 for SMS August 2012.

[14] Amol Deshpande and Vikrant Bhor, Smart Garbage Management System.

[15] S. Singhal and S. Pandey, "Solid waste management in India: Status and future directions".

[16] M.Sharholy, K.Ahmad, G.Mahmood and R.C. Trivedi, "Municipal solid waste management in Indian cities.

[17] X. Ma, X. Chen, A. Khokar, and D. Schonfeld, Motion trajectorybased vide. 